\title{
Spectroscopic Evidence for the Involvement of a Radical Intermediate in the Friedel-Crafts Benzylation Using Ion-Exchanged K10 Catalysts
}

\author{
Zoltán Hell, László Korecz², Sándor Békássy† \\ 1 Department of Organic Chemistry and Technology, Faculty of Chemical Technology and Biotechnology, \\ Budapest University of Technology and Economics, H-1521 Budapest, P. O. Box 91., Hungary \\ 2 Institute of Materials and Environmental Chemistry, Research Centre for Natural Sciences, Hungarian Academy of Sciences, \\ 1117 Budapest, Magyar tudósok körútja 2., Hungary \\ ${ }^{*}$ Corresponding author, e-mail: zhell@mail.bme.hu
}

Received: 12 July 2018, Accepted: 30 September 2018, Published online: 20 November 2018

\begin{abstract}
For Friedel-Crafts alkylation of aromatic hydrocarbons an ionic reaction path is considered as classical reaction mechanism. The alkylation with benzyl chloride in the presence of ion-exchanged K10 montmorillonite catalysts containing multivalent, reducible cations had an outstanding activity, therefore a radical initial step as a supplement to the ionic mechanism was proposed earlier. We made ESR investigations to clarify the existence and the nature of the suggested radical species. The ESR experiments verified that the reaction involves a radical step.
\end{abstract}

Keywords

Friedel-Crafts alkylation, benzylation, radical step, ESR spectroscopy

\section{Introduction}

Friedel-Crafts reaction is one of the most important reactions of organic chemistry and chemical industry $[1,2]$. It serves to functionalize aromatic compounds, providing useful intermediates of different classes of materials, such as pharmaceuticals, dyes, surfactants, and agrochemicals. Nowadays instead of the traditional Lewis acids $\left(\mathrm{AlCl}_{3}\right.$, $\mathrm{FeCl}_{3}, \mathrm{ZnCl}_{2}$ ) heterogeneous acid catalysts are used more and more in these reactions [3], in order to facilitate the separation of the catalyst as well as the work-up of the reaction mixture, to avoid the corrosion and the formation of large amount of waste water, and yielding environmentally more bening processes. A great number of acidic heterogeneous catalysts are suitable for Friedel-Crafts reactions (see e.g. the list in [4]), the use of the clay-based ones is very advantageous because of the good activity, low price and simple preparation process.

We investigated in detail the alkylation of benzene and toluene with benzyl alcohol as well as benzyl chloride, using ion-exchanged K10 clays as catalysts [5]. The kinetic evaluation of the reactions showed that using benzyl alcohol as alkylating agent the initial reaction rate was proportional to the Brønsted acidity of the catalysts, but in the case of benzyl chloride there was no correlation between the reaction rate and neither the Brønsted, nor the Lewis acidity. At the same time in this latter reaction the catalysts containing multivalent, reducible cations $\left(\mathrm{Fe}^{3+}\right.$, $\mathrm{Cu}^{2+}, \mathrm{Sn}^{2+}$ ) had an outstanding activity. This observation suggested that the reaction involves an oxido-reductive process, therefore we have proposed a radical initial step as a supplement to the classical ionic mechanism.

Exactly the same radical part-process was proposed later by Choudary et al. [6], without mentioning at all our precedent proposition.

The possibility of a radical step has arisen also on the basis of other reactions carried out in the presence of claybased catalysts, in liquid phase, where the presence of radicals or radical cations was proved: nitration of aromatic hydrocarbons or phenols [7-10], Diels-Alder reaction between methyl acrylate and cyclopentadiene [11].

Three probable mechanistic interpretations can be found in the literature for benzylation of aromatic hydrocarbons with benzyl chloride on solid acid based supported metal catalysts, without any direct (preparative or spectroscopic) experimental verification: a simple radical 
step [12-17] - see Scheme 1; the presence of a benzyl chloride radical cation [4, 18-25] - see Scheme 2; or the presence of a benzyl radical cation [26-28] as intermediate - see Scheme 3. In some cases the same authors have different suggestions for similar catalytic systems.

For an experimental support of our proposition and for the shake of orientation between the three suggested mechanism variants we have investigated by ESR spectroscopy whether a radical is formed in the reaction, and in a positive case what is its structure.

\section{Results and discussion}

Mixing benzyl chloride, toluene and $\mathrm{Fe}^{3+}-\mathrm{K} 10$ clay in an ESR tube a sharp singlet appeared even at room temperature at $\mathrm{g}=2.0037$ with $20 \mathrm{G}$ linewidth (Fig. 1). This is characteristic to a carbon-type radical. Since the signal

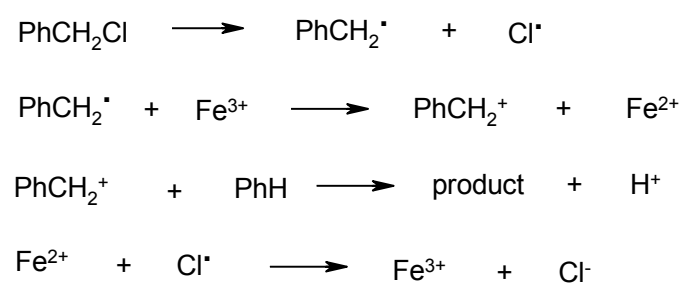

Scheme 1 Proposed reaction mechanism for Friedel-Crafts benzylation of benzene with benzyl chloride over iron-containing mesoporous TUD-1 catalyst [12].

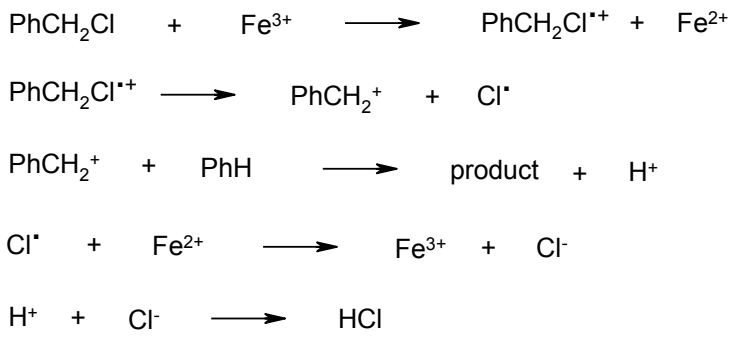

Scheme 2 Proposed reaction mechanism for Friedel-Crafts benzylation of benzene with benzyl chloride over iron-modified ZSM-5 zeolites [18].

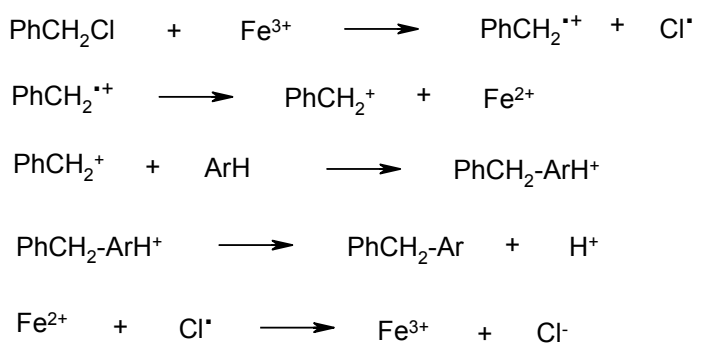

Scheme 3 Proposed reaction mechanism for Friedel-Crafts benzylation of benzene with benzyl chloride over iron mesoporous silicas [28].

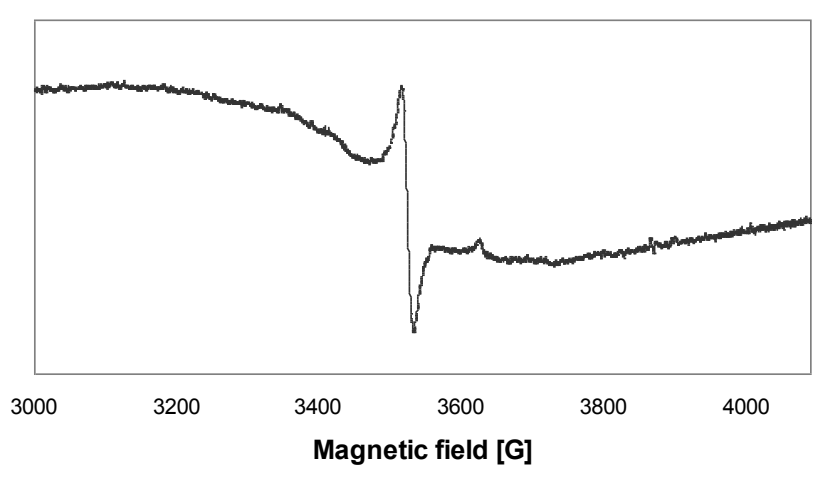

Fig. 1 Signal obtained in the reaction of benzyl chloride with toluene in the presence of $\mathrm{Fe}^{3+}-\mathrm{K} 10$.

was obtained also when toluene was omitted from the reaction mixture, the radical can be unambiguously originated from benzyl chloride. Nevertheless, a benzyl-type radical should show multiplicity. The large linewidth and the lack of multiplicity can be explained with either the solid surface of the catalyst or the oxygen adsorbed on the bulk solid phase which can hinder the splitting of the signal. The intensive evolution of $\mathrm{HCl}$ which resulted the foaming of the mixture in the sample tube might also disturbed the observation of a clear liquid phase. The evolution of the signal was quite fast, and the signal reached a maximum after about a half an hour (Fig. 2).

The formation of the radical was continuous, after a fast rise its concentration reached a maximum value (Fig. 3, left). Simultaneously, the concentration of $\mathrm{Fe}^{3+}$ in the solution reached a maximum (Fig. 3, right).

Next we examined the other metal-modified K10 catalysts, the reaction of which showed outstanding reactivity in our former benzylation experiments [5]. Thus, when $\mathrm{Sn}^{2+}-\mathrm{K} 10$ was used instead of $\mathrm{Fe}^{3+}-\mathrm{K} 10$, a similar signal having the same $g$ value and linewidth was detected (Fig. 4).

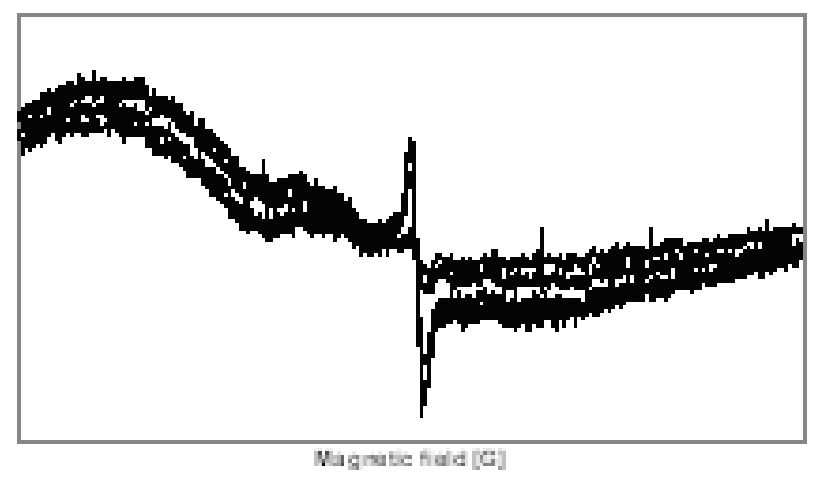

Fig. 2 Evolution of the signal detected in the reaction of benzyl chloride with toluene in the presence of $\mathrm{Fe}^{3+}-\mathrm{K} 10$ in the range of $0-1508 \mathrm{sec}$. 

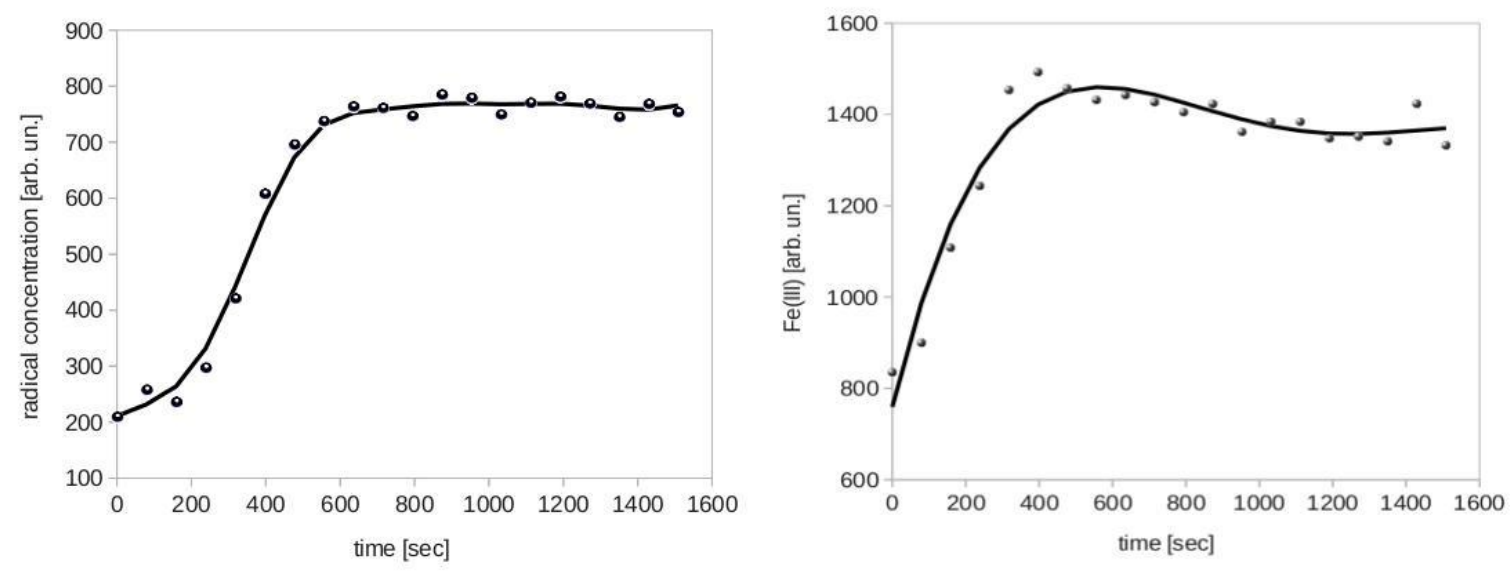

Fig. 3 Evolution of the concentration of the radical (left) and the $\mathrm{Fe}^{3+}$ ion (right) in the sample.

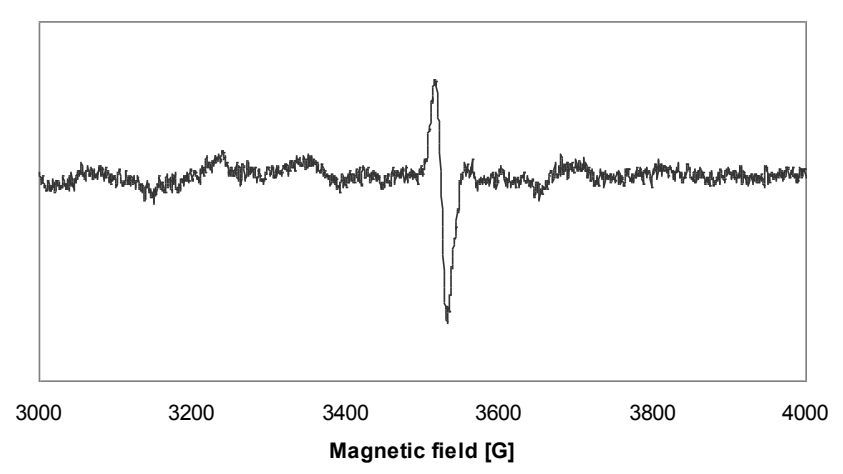

Fig. 4 Signal obtained in the reaction of benzyl chloride with toluene in the presence of $\mathrm{Sn}^{2+}-\mathrm{K} 10$.

The other catalysts, which showed enhanced reactivity in the Friedel-Crafts alkylation of benzene or toluene with benzyl chloride, were the copper- and manganese-modified K10 clays. These metals have a strong disturbing effect on the ESR-measurements. However, we could detect the same signal when benzyl chloride was treated with $\mathrm{Cu}^{2+}-\mathrm{K} 10$ and $\mathrm{Mn}^{2+}-\mathrm{K} 10$ (Fig. 5).

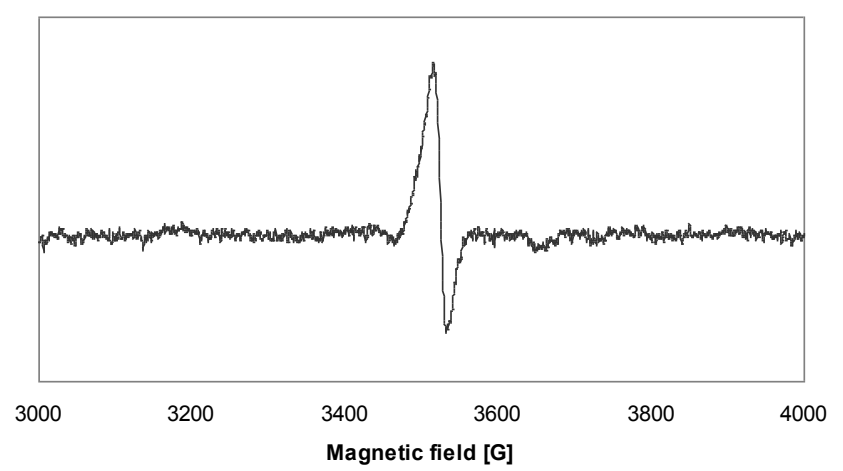

These experiments support our initial hypothesis [5] on a radical step in clay-catalysed Friedel-Crafts benzylation with benzyl chloride. The signals obtained, however, could not help in the exact determination of the nature of the radical. Thus DFT calculations were made [29] to decide between a benzyl radical or a benzyl radical cation (see Schemes 1 and 3). The spectra were calculated with 1 $\mathrm{G}$ linewidth (this gives better approximation of the shape of the signal) and to minimal energy (this estimates better the linewidth). The results are shown on Fig. 6.

The linewidth of the calculated signal is more comparable with the measured linewidth in the case of the benzyl radical. For the benzyl radical cation the difference between the calculated and measured linewidth is unreally big. The lack of the splitting in the case of benzyl radical can be explained with the disturbing effects during the measurement indicated above (foaming, the solid surface and the oxygen adsorbed on this surface). Thus we can suppose that from the previous proposition described for this type of Friedel-Crafts alkylation the mechanism depicted in Scheme 1 may describe the run of the reaction.

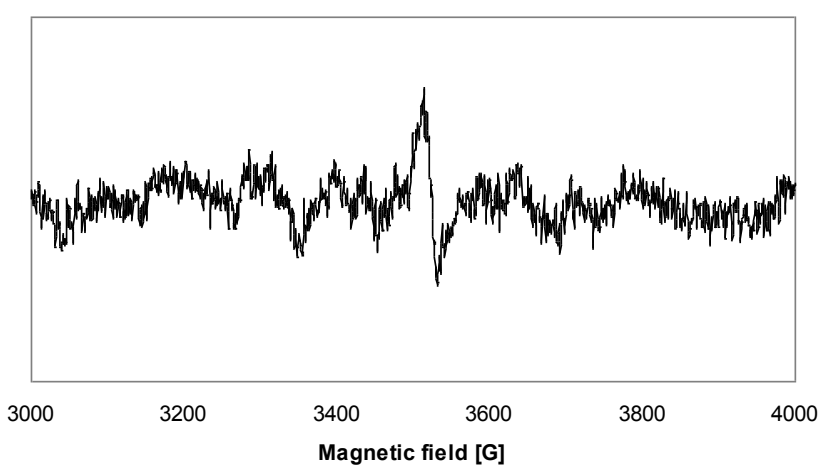

Fig. 5 Signal obtained in the reaction of benzyl chloride with toluene in the presence of $\mathrm{Cu}^{2+}-\mathrm{K} 10$ (left) and $\mathrm{Mn}^{2+}-\mathrm{K} 10$ (right). 

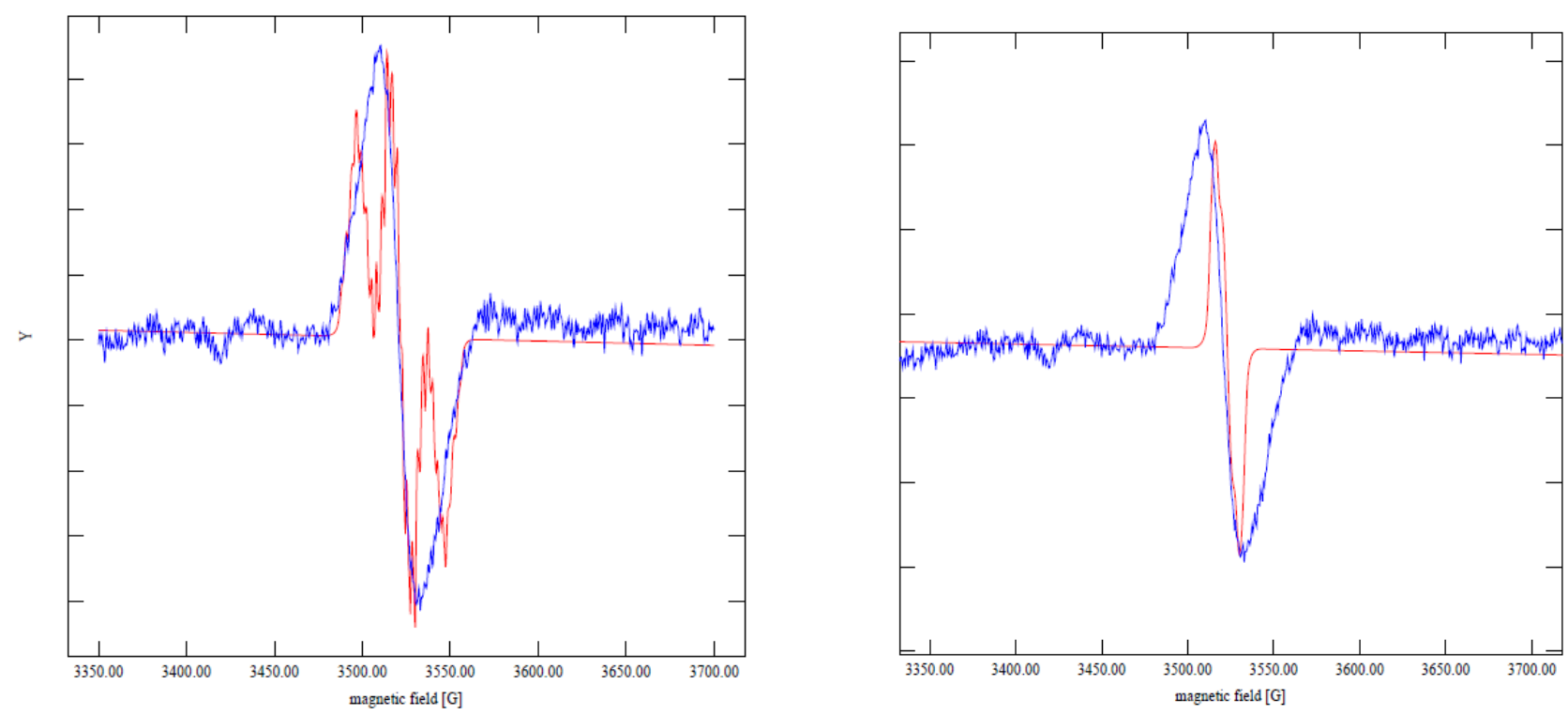

Fig. 6 Comparison of the measured signal and the signal calculated for benzyl radical (left) and benzyl radical cation (right) (blue: measured signal, red: calculated signal).

\section{Experimental}

\subsection{Generalities}

Benzyl chloride and toluene were purchased from Merck Ltd. Hungary. K10 montmorillonite was the product of Süd-Chemie (Germany).

${ }^{1} \mathrm{HNMR}$ spectrum was recorded on a Bruker Avanche-300 spectrometer. The sample was dissolved in $\mathrm{CDCl}_{3}$. Chemical shifts are given on a $\delta$ scale, $\delta(\mathrm{TMS})=0 \mathrm{ppm}$.

ESR spectra were recorded on a Bruker EleXsys 500 instrument. $100 \mathrm{~K}$ modulation frequency, $10 \mathrm{G}$ modulation and $10 \mathrm{~mW}$ microwave power were used.

TLC-s were developed on Merck Kieselgel $60 \mathrm{~F}_{254}$ plates with hexane/acetone (4:1) eluent.

\subsection{Preparation of the catalysts}

K10 clay was exchanged as described earlier [5] with $\mathrm{Cu}^{2+}, \mathrm{Fe}^{3+}, \mathrm{Mn}^{2+}$, and $\mathrm{Sn}^{2+}$. Thus the clay was gradually added to a stirred aqueous solution of the chloride of the cation at room temperature for $24 \mathrm{~h}$. After the exchange the suspensions were filtered and washed with deionized water to eliminate the physisorbed salts. The resulting solids were dried on a thin layer at $373 \mathrm{~K}$ and ground. The thus obtained K10 catalysts are designated as $\mathrm{Me}^{\mathrm{n}+}-\mathrm{K} 10$.

\subsection{Reaction of benzyl chloride with toluene}

The mixture of $0.79 \mathrm{~g}\left(0.72 \mathrm{~cm}^{3}, 6.25 \mathrm{mmol}\right)$ benzyl chloride and $0.1 \mathrm{~g} \mathrm{Me}^{\mathrm{n}+}-\mathrm{K} 10$ in $10 \mathrm{~cm}^{3}$ toluene was stirred at $80{ }^{\circ} \mathrm{C}$ for $3.5 \mathrm{~h}$ (complete consumption of benzyl chloride, checked by TLC). Then the solid was filtered off, the filtrate was evaporated. The residue was subjected to a ${ }^{1} \mathrm{H}$ NMR analysis. The spectral data showed the presence of 1-benzyl-2-methylbenzene and 1-benzyl-4-methylbenzene in a 1:1 ratio. $\delta: 2.21(\mathrm{~s}, 3 \mathrm{H}), 2.28(\mathrm{~s}, 3 \mathrm{H}), 3.91(\mathrm{~s}, 2 \mathrm{H})$, 3.95(s, 2H), 7.04-7.25(m, 18H).

\subsection{ESR experiments}

Benzyl chloride, toluene and $\mathrm{Fe}^{3+}-\mathrm{K} 10$ montmorillonite was placed in an ESR tube. Vigorous evolution of $\mathrm{HCl}$ was observed after a few minutes even at room temperature. The experiments were repeated with $\mathrm{Sn}^{2+}-\mathrm{Cu}^{2+}-$, and $\mathrm{Mn}^{2+}$-modified $\mathrm{K} 10$, too. In every case a well-developed ESR signal was detected.

\section{Conclusions}

ESR experiments verified that the Friedel-Crafts reaction of toluene with benzyl chloride in the presence of K10 clay modified with $\mathrm{Fe}^{3+}, \mathrm{Cu}^{2+}, \mathrm{Mn}^{2+}$ or $\mathrm{Sn}^{2+}$ ions involves a

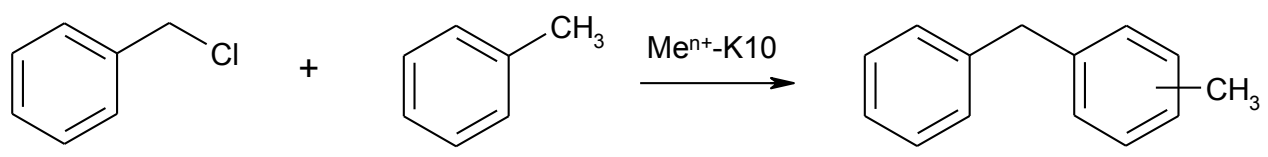

Scheme 4 Reaction of benzyl chloride with toluene in the presence of modified K10 clay 
radical step. Based on the ESR spectra and theoretical calculations, this radical may be a benzyl radical.

\section{Acknowledgements}

The authors express their gratitude to Prof. François FIGUERAS (Institut de Recherches sur la Catalyse et l'Environnement de Lyon, France) for the long successful cooperation in the field of research.

\section{References}

[1] Olah, G. A., Molnár, Á., Prakash, G. K. S. "Hydrocarbon Chemistry", 3rd ed., Wiley, New York, 2018.

[2] Mayer, Sz., Keglevich, P., Ábrányi-Balogh, P., Szigetvári, Á., Dékány, M., Szántay, Cs. Jr., Hazai, L. "Attempted Diels-Alder Reactions on Vindoline Derivatives", Periodica Polytechnica Chemical Engineering, 61(4), pp. 258-263, 2017.

https://doi.org/10.3311/PPch.11087

[3] Perego, C., Ingallina, P. "Recent advances in the industrial alkylation of aromatics: new catalysts and new processes", Catalysis Today, 73(1-2), pp. 3-22, 2002.

https://doi.org/10.1016/S0920-5861(01)00511-9

[4] Bachari, K., Cherifi, O. "Benzylation of aromatics on tin-containing mesoporous materials", Applied Catalysis A: General, 319, pp. 259-266, 2007.

https://doi.org/10.1016/j.apcata.2006.12.010

[5] Cseri, T., Békássy, S., Figueras, F., Rizner, S. "Benzylation of aromatics on ion-exchanged clays", Journal of Molecular Catalysis A: Chemical, 98(2), pp. 101-107, 1995.

https://doi.org/10.1016/1381-1169(95)00016-X

[6] Choudary, B. M., Kantam, M. L., Sateesh, M., Rao, K. K., Santhi, P. L. "Iron pillared clays - efficient catalysts for FriedelCrafts reactions", Applied Catalysis A: General, 149(1), pp. 257264, 1997.

https://doi.org/10.1016/S0926-860X(96)00310-9

[7] Pokhodenko, V. D., Khizhnyi, V. A., Koshechko, V. G., Shkrebtii, O. I. "Single-electron transfer event in electrophilic reactions of substituted phenols", Zhurnal Organicheskoi Khimii, 11, pp. 18731876, 1975.

[8] Perrin, C. L. "Necessity of electron transfer and a radical pair in the nitration of reactive aromatics", Journal of the American Chemical Society, 99(16), pp. 5516-5518, 1977. https://doi.org/10.1021/ja00458a065

[9] Laszlo, P. "Catalysis of organic reactions by inorganic solids", Accounts of Chemical Research, 19(4), pp. 121-127, 1986. https://doi.org/10.1021/ar00124a004

[10] Laszlo, P. "Chemical Reactions on Clays", Science, 235(4795), pp. 1473-1477, 1987. https://doi.org/10.1126/science.235.4795.1473

[11] Cativiela, C., Fraile, J. M., Garcia, J. I., Mayoral, J. A., Figueras, F., De Menorval, L. C., Alonso, P. J. "Factors influencing the k10 montmorillonite-catalyzed diels-alder reaction between methyl acrylate and cyclopentadiene", Journal of Catalysis, 137(2), pp. 394-407, 1992.

https://doi.org/10.1016/0021-9517(92)90167-G
† In memoriam Sándor Békássy

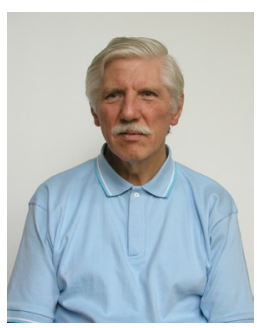

[12] Hamdy, M. S., Mul, G., Jansen, J. C., Ebaid, A., Shan, Z., Overweg, A. R., Maschmeyer, Th. "Synthesis, characterization, and unique catalytic performance of the mesoporous material Fe-TUD-1 in Friedel-Crafts benzylation of benzene", Catalysis Today, 100(34), pp. 255-260, 2005. https://doi.org/10.1016/j.cattod.2004.10.018

[13] Bachari, K., Cherifi, O. "Benzylation of benzene and other aromatics by benzyl chloride over copper-mesoporous molecular sieves materials", Catalysis Communications, 7(12), pp. 926-930, 2006. https://doi.org/10.1016/j.catcom.2006.03.014

[14] Bachari, K., Cherifi, O. "Gallium-containing mesoporous silicas as a catalyst for alkylation of benzene and other aromatics by benzyl chloride", Journal of Molecular Catalysis A: Chemical, 253(1-2), pp. 187-191, 2006.

https://doi.org/10.1016/j.molcata.2006.03.040

[15] Bachari, K., Cherifi, O. "Zinc-containing mesoporous silicas as a catalyst for the benzylation of benzene and other aromatics by benzyl chloride", Kinetics and Catalysis, 48(3), pp. 398-402, 2007. https://doi.org/10.1134/S0023158407030081

[16] Bachari, K., Cherifi, O. "Application of the Indium-containing mesoporous silicas catalysts in the alkylation of aromatics reaction", Journal of Porous Materials, 15(3), pp. 325-330, 2008. https://doi.org/10.1007/s10934-006-9093-Z

[17] Anand, C., Srinivasu, P., Alam, S., Balasubramanian, V. V., Sawant, D. P., Palanichamy, M., Murugesan, V., Vinu, A. "Highly active three-dimensional cage type mesoporous ferrosilicate catalysts for the Friedel-Crafts alkylation", Microporous and Mesoporous Materials, 111(1-3), pp. 72-79, 2008. https://doi.org/10.1016/j.micromeso.2007.07.011

[18] Choudhary, V. R., Jana, S. K. "Benzylation of benzene and substituted benzenes by benzyl chloride over $\mathrm{InCl}_{3}, \mathrm{GaCl}_{3}, \mathrm{FeCl}_{3}$ and $\mathrm{ZnCl}_{2}$ supported on clays and Si-MCM-41", Journal of Molecular Catalysis A: Chemical, 180(1-2), pp. 267-276, 2002. https://doi.org/10.1016/S1381-1169(01)00447-2

[19] Díaz, E., Ordóñez, S., Vega, A., Auroux, A., Coca, J. "Benzylation of benzene over Fe-modified ZSM-5 zeolites: Correlation between activity and adsorption properties", Applied Catalysis A: General, 295(2), pp. 106-115, 2005. https://doi.org/10.1016/j.apcata.2005.07.059

[20] Belkhadem, F., Clacens, J.-M., Bengueddach, A., Figueras, F. "Acidity and catalytic properties for the alkylation of aromatics of PILCs with mixed oxide pillars prepared from two different bentonites", Applied Catalysis A: General, 298, pp. 188-193, 2006. https://doi.org/10.1016/j.apcata.2005.10.007 
[21] Bachari, K., Cherifi, O. "Study of the benzylation of benzene and other aromatics by benzyl chloride over transition metal chloride supported mesoporous SBA-15 catalysts", Journal of Molecular Catalysis A: Chemical, 260(1-2), pp. 19-23, 2006. https://doi.org/10.1016/j.molcata.2006.06.042

[22] Bidart, A. M. F., Borges, A. P. S., Chagas, H. C., Nogueira, L., Lachter, E. R., Mota, C. J. A. "Mechanistic aspects of FriedelCrafts alkylation over FeY zeolite", Journal of the Brazilian Chemical Society, 17(4), pp. 758-762, 2006. https://doi.org/10.1590/S0103-50532006000400018

[23] Hentit, H., Bachari, K., Ouali, M. S., Womes, M., Benaichouba, B., Jumas, J. C. "Alkylation of benzene and other aromatics by benzyl chloride over iron-containing aluminophosphate molecular sieves", Journal of Molecular Catalysis A: Chemical, 275(1-2), pp. 158-166, 2007. https://doi.org/10.1016/j.molcata.2007.05.032

[24] Tahir, N., Abdelssadek, Z., Halliche, D., Saadi, S., Chebout, R., Cherifi, O., Bachari, K. "Mg-Fe-hydrotalcite as catalyst for the benzylation of benzene and other aromatics by benzyl chloride reactions", Surface and Interface Analysis, 40(3-4), pp. 254-258, 2008. https://doi.org/10.1002/sia.2695
[25] Bachari, K., Touileb, A., Cherifi, O. "Catalytic properties of antimony-SBA-15 materials in the benzylation of aromatics reactions", Kinetics and Catalysis, 50(3), pp. 407-413, 2009. https://doi.org/10.1134/S0023158409030112

[26] Bachari, K., Millet, J. M. M., Benaïchouba, B., Cherifi, O., Figueras, F. "Benzylation of benzene by benzyl chloride over iron mesoporous molecular sieves materials", Journal of Catalysis, 221(1), pp. 55-61, 2004.

https://doi.org/10.1016/S0021-9517(03)00295-1

[27] Bachari, K., Millet, J. M. M., Bonville, P., Cherifi, O., Figueras, F. "Spectroscopic characterization of iron nanoparticles in Fe-mesoporous silicate catalysts", Journal of Catalysis, 249(1), pp. $52-58,2007$. https://doi.org/10.1016/j.jcat.2007.03.028

[28] Arafat, A., Alhamed, Y. "Catalytic activity of mesoporous catalysts in Friedel-Crafts benzylation of benzene", Journal of Porous Materials, 16(5), pp. 565-572, 2009. https://doi.org/10.1007/s10934-008-9241-8

[29] Neese, F. "The ORCA program system", WIREs Computational Molecular Science, 2(1), pp. 73-78, 2012. https://doi.org/10.1002/wcms. 81 